\title{
A bacterial artificial chromosome library for the Australian saltwater crocodile (Crocodylus porosus) and its utilization in gene isolation and genome characterization
} Xueyan Shan 1 , David A Ray², John A Bunge ${ }^{3}$ and Daniel G Peterson*1,4

Address: ${ }^{1}$ Mississippi Genome Exploration Laboratory (MGEL), Department of Plant and Soil Sciences, Mississippi State University, Mississippi State, MS, USA, ${ }^{2}$ Department of Biology, West Virginia University, Morgantown, WV, USA, ${ }^{3}$ Department of Statistical Science, Cornell University, Ithaca, NY, USA and ${ }^{4}$ Life Sciences \& Biotechnology Institute; Institute for Digital Biology, Mississippi State University, Mississippi State, MS, USA

Email: Xueyan Shan - xshan@pss.msstate.edu; David A Ray - david.ray@mail.wvu.edu; John A Bunge - jab18@cornell.edu; Daniel G Peterson* - dpeterson@pss.msstate.edu

* Corresponding author

from Avian Genomics Conference and GO Annotation Workshop

Starkville, MS, USA. 19-22 May 2008

Published: 14 July 2009

BMC Genomics 2009, I0(Suppl 2):S9 doi:10.1186/1471-2164-10-S2-S9

This article is available from: http://www.biomedcentral.com/I47I-2/64/I0/S2/S9

(C) 2009 Shan et al; licensee BioMed Central Ltd.

This is an open access article distributed under the terms of the Creative Commons Attribution License (http://creativecommons.org/licenses/by/2.0), which permits unrestricted use, distribution, and reproduction in any medium, provided the original work is properly cited.

\begin{abstract}
Background: Crocodilians (Order Crocodylia) are an ancient vertebrate group of tremendous ecological, social, and evolutionary importance. They are the only extant reptilian members of Archosauria, a monophyletic group that also includes birds, dinosaurs, and pterosaurs. Consequently, crocodilian genomes represent a gateway through which the molecular evolution of avian lineages can be explored. To facilitate comparative genomics within Crocodylia and between crocodilians and other archosaurs, we have constructed a bacterial artificial chromosome (BAC) library for the Australian saltwater crocodile, Crocodylus porosus. This is the first BAC library for a crocodile and only the second BAC resource for a crocodilian.

Results: The $C$. porosus BAC library consists of 101,760 individually archived clones stored in 384-well microtiter plates. Notl digestion of random clones indicates an average insert size of $102 \mathrm{~kb}$. Based on a genome size estimate of $2778 \mathrm{Mb}$, the library affords 3.7 fold $(3.7 \times)$ coverage of the $C$. porosus genome. To investigate the utility of the library in studying sequence distribution, probes derived from $C R I a$ and $C R I b$, two crocodilian CRI-like retrotransposon subfamilies, were hybridized to $C$. porosus macroarrays. The results indicate that there are a minimum of $20,000 \mathrm{CRIa} / \mathrm{b}$ elements in $C$. porosus and that their distribution throughout the genome is decidedly non-random. To demonstrate the utility of the library in gene isolation, we probed the $C$. porosus macroarrays with an overgo designed from a $C$-mos (oocyte maturation factor) partial cDNA. A BAC containing C-mos was identified and the $C$-mos locus was sequenced. Nucleotide and amino acid sequence alignment of the $C$. porosus $C$-mos coding sequence with avian and reptilian $C$-mos orthologs reveals greater sequence similarity between $C$. porosus and birds (specifically chicken and zebra finch) than between $C$. porosus and squamates (green anole).

Conclusion: We have demonstrated the utility of the Crocodylus porosus BAC library as a tool in genomics research. The BAC library should expedite complete genome sequencing of $C$. porosus and facilitate detailed analysis of genome evolution within Crocodylia and between crocodilians and diverse amniote lineages including birds, mammals, and other non-avian reptiles.
\end{abstract}




\section{Background}

Crocodilians (Order Crocodylia) are a group of reptiles that originated roughly 200 million years ago [1,2]. They are apex predators in the marine and freshwater habitats in which they reside, and they play a major role in warmwater ecosystems throughout the world. There are 23 extant species grouped into three families - Crocodilidae (crocodiles), Alligatoridae (alligators and caimans), and Gavialidae (gharials) [3,4]. As evidenced by their frequent appearances in video documentaries and television programs, crocodilians are a subject of considerable human curiosity. Moreover, these reptiles have been common subjects/characters in mythology, folk tales, art (including cave paintings and hieroglyphics), and literature suggesting that they have considerable symbolic and practical significance in the lives of humans, past and present.

Crocodilians, birds, dinosaurs, and pterosaurs form a monophyletic group known as the Archosauria [5] of which only the crocodilian and the avian lineages are extant (Figure 1). In support of this premise, molecular phylogenetic evidence from nuclear and mitochondrial DNA sequencing indicates that crocodilians and birds are indeed each other's closest living relatives [5,6]. Among archosaurs, only the chicken and zebra finch have been the focus of complete genome sequencing efforts $[7,8]$. Genome level analyses of a crocodilian would be especially useful in leveraging information from the chicken, and a crocodilian genome would be the best possible outgroup for all genomic work within birds. However, with the modest exception of Alligator mississippiensis for which there is roughly $2.5 \mathrm{Mb}$ of BAC end sequence [9] and 26 partially assembled BACs (GenBank, 10/3/2008), little sequence data is available for crocodilian genomes, in part due to a relative lack of high-quality molecular tools for this important clade.

For roughly 15 years, bacterial artificial chromosome (BAC) libraries have been the principal molecular substrate used in physical mapping and complete eukaryote genome sequencing [10]. Gridding of ordered BAC libraries (i.e., libraries in which each clone is stored in its own microtiter well) onto macroarrays and multiplex screening techniques have facilitated rapid gene isolation. The utility of BAC clones as substrates for end sequencing, in conjunction with advanced DNA fingerprinting techniques and macroarray analysis, has permitted construction of robust physical maps and selection of minimum tiling paths (i.e., sets of minimally overlapping BAC clones spanning entire chromosomes or chromosomal regions) for accurate genome sequencing and assembly. Recent advances in sequencing technologies (e.g., 454 pyrosequencing, Illumina sequencing, etc.) have created powerful opportunities in which ordered BAC libraries play a critical role. A particularly promising strategy for

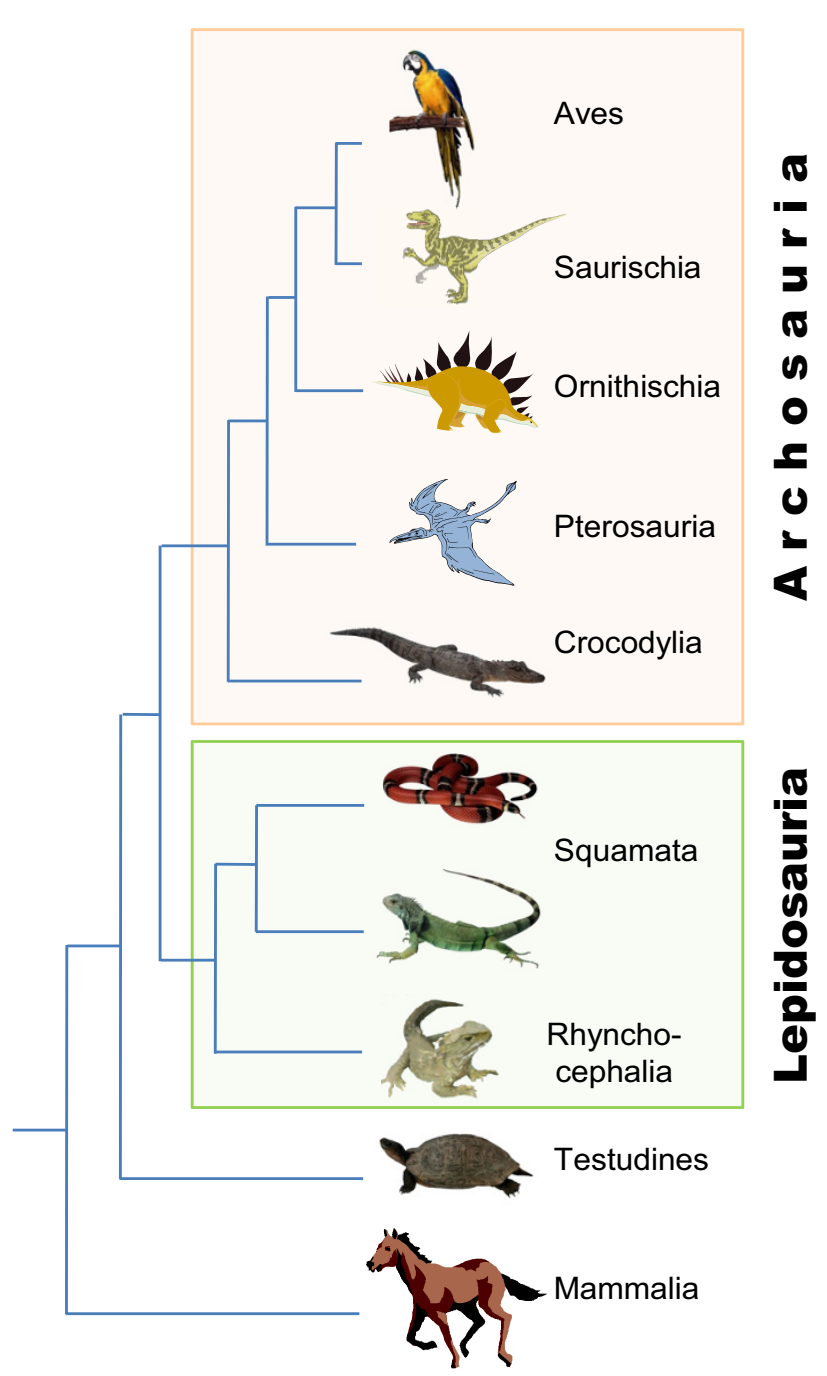

Figure I

A tree depicting potential relationships among amniotes. Some relationships, especially the placement of Testudines [6,36], are controversial.

simultaneous physical mapping and sequencing of large eukaryotic genomes involves sequencing pools of sheared, individually "bar coded" BAC clones. After sequencing, those reads sharing a bar code (i.e., corresponding to the same BAC) are grouped together and assembled in silico, and physical maps are constructed by identifying overlapping assembled or partially assembled BAC sequences [11].

To expedite genome research in crocodilians, we have constructed a BAC library for the Australian saltwater crocodile (Crocodylus porosus). The C. porosus library is only the second large-insert DNA library for a crocodilian - a $10 \times$ library exists for Alligator mississippiensis [12] - and the only BAC library for Crocodilidae, the largest of the croc- 
odilian families. C. porosus is the largest living crocodilian and, along with A. mississippiensis, the only crocodilian species to be commercially farmed. Here we describe generation and characterization of the C. porosus BAC library and demonstrate its utility as a tool for gene isolation, genome characterization, and comparative genomics.

\section{Methods \\ Preparation of nuclei agarose plugs from crocodile blood sample}

Whole blood was obtained from Errol, a male C. porosus from the Darwin Crocodile Farm [13] near Darwin, Australia. Blood was suspended in citrate buffer $(250 \mathrm{mM}$ sucrose, $40 \mathrm{mM}$ trisodium citrate, $\mathrm{pH} 7.6$ ) containing $5 \%$ $\mathrm{v} / \mathrm{v}$ dimethylsulfoxide, aliquoted into $1.5 \mathrm{ml}$ polypropylene tubes, flash frozen in liquid nitrogen, and shipped to the Mississippi Genome Exploration Laboratory [14]. One of the tubes was thawed on ice and centrifuged at $4,000 \mathrm{rpm}$ in a microcentrifuge for $4 \mathrm{~min}$. The supernatant was decanted, the pellet was gently re-suspended in 1 $\mathrm{ml}$ of STEX buffer (100 mM NaCl, $100 \mathrm{mM}$ Tris-HCl, 100 mM EDTA, pH 8.0), and the mixture was centrifuged as described above. The blood cell pellet was re-suspended in $500 \mu \mathrm{l}$ STEX buffer and placed in a water bath at $45^{\circ} \mathrm{C}$. After $15 \mathrm{~min}$, the blood suspension was mixed with an equal volume of $45^{\circ} \mathrm{C} 2 \% \mathrm{w} / \mathrm{v}$ Cambrex (Rockland, ME) SeaPlaque Agarose (cat. no. 50100) in STEX buffer. The mixture was poured into a small Petri dish so that the depth of the solution was roughly $2 \mathrm{~mm}$. After $20 \mathrm{~min}$ at $4^{\circ} \mathrm{C}$, the resulting gel was cut into $10 \times 5 \mathrm{~mm}$ rectangles, and these "plugs" were transferred into a conical $50 \mathrm{ml}$ polypropylene tube containing $40 \mathrm{ml}$ of lysis buffer (STEX buffer containing 1\% w/vN-lauroylsarcosine and $300 \mathrm{mg} /$ $\mathrm{ml}$ proteinase $\mathrm{K})$. The capped tube was incubated at $37^{\circ} \mathrm{C}$ overnight with gentle agitation. Plugs were transferred into $0.5 \mathrm{M}$ EDTA ( $\mathrm{pH} 8.0$ ) containing $0.1 \mathrm{M}$ phenylmethylsulfonyl fluoride and incubated at $4{ }^{\circ} \mathrm{C}$ for one hour. Plugs were washed in 0.5 MEDTA $(\mathrm{pH} \mathrm{8.0)}$ and then stored at $4^{\circ} \mathrm{C}$ in this buffer.

\section{Preparation of high-molecular-weight insert DNA}

A few test DNA plugs were exposed to different HindIII concentrations to determine conditions providing the largest number of fragments between 100 to $500 \mathrm{~kb}$ [see [15]]. The optimal enzyme concentration as determined in the test digests was used in a large-scale partial digest. Plugs used in the mass digestion were macerated and placed in a slot well of a 1\% w/v Cambrex SeaKem Gold Agarose (cat. no. 50150) gel in $0.25 \times$ TBE buffer $(22.5$ mM Tris, $22.5 \mathrm{mM}$ boric acid, $0.5 \mathrm{mM}$ EDTA, pH 8.0). Size selection of partially digested DNA was performed using pulsed-field gel electrophoresis (PFGE) according to Chalhoub et al. [16]. Size-selected HindIII fragments between 100 and $500 \mathrm{~kb}$ were recovered from agarose by electroelution according to Peterson et al. [15].

\section{BAC library construction}

BAC library construction was performed as described in Peterson et al. [15] using the pIndigoBAC-5 vector (Epicentre, Madison WI) and ElectroMAX DH10B T1 PhageResistant Competent Cells (Invitrogen, Carlsbad, CA). Clone picking and library replication were performed using a Genetix QPixII robot (New Milton, Hampshire, $\mathrm{UK})$. To monitor the quality of the BAC library and determine mean insert size, 96 BAC clones from every fiftieth 384-well plate were evaluated by NotI digestion and PFGE. For these analyses BAC DNA was isolated using an AutoGenprep 960 robot (AutoGen, Holliston, MA).

\section{Macroarray construction}

High density macroarrays were prepared using a Genetix QPixII robot. Each array consisted of 18,432 double-spotted BAC clones stamped onto a $22.5 \mathrm{~cm}^{2}$ Hybond $\mathrm{N}^{+}$filter (GE Healthcare, Piscataway, NJ). There were enough $C$. porosus BAC clones to produce five complete macroarrays $(101,760$ clones $\div 18,432$ clones/macroarray $=5.52)$. Stamped arrays were placed clone-side up on LB (LuriaBertani) agar containing $12.5 \mathrm{mg} / \mathrm{L}$ chloramphenicol and incubated at $37^{\circ} \mathrm{C}$ overnight. Each macroarray was fixed via incubation in $0.5 \mathrm{~N} \mathrm{NaOH}, 1.5 \mathrm{M} \mathrm{NaCl}$ for $7 \mathrm{~min}$ followed by incubation in $1.5 \mathrm{M} \mathrm{NaCl}, 0.5 \mathrm{M}$ Tris $\mathrm{Cl}$ for 7 min. The membranes were allowed to air dry for $1 \mathrm{~h}$, treated with $0.4 \mathrm{~N} \mathrm{NaOH}$ for $20 \mathrm{~min}$, and washed in $5 \times$ SSPE (0.75 M NaCl, $50 \mathrm{mM} \mathrm{Na} \mathrm{HPO}_{4}, 5$ mM EDTA, pH 7.4) for $7 \mathrm{~min}$. Macroarrays were air dried and stored in sealed plastic bags.

\section{Probe design and BAC library screening}

Overgo probes [17] were designed from the consensus sequences of CR1a and CR1b (see Additional File 1, Table S1), two recently active CR1 subfamilies present in the genomes of Crocodylus moreletii and Osteolaemus tetraspis (D. Ray, unpublished data), and from a partial cDNA sequence of the $C$. porosus C-mos gene [GenBank:AF478196]. The overgos (Table 1) were labeled with $32 \mathrm{P}$ and hybridized to macroarrays as previously described $[18,19]$. Probe hybridization images were recorded and analyzed using a Storm 820 (GE Healthcare, Piscataway, NJ) phosphoimager. For the CR1-probed macroarrays, the spot densitometry tool in AlphaEaseFC, Version 3.3.0 (Alpha Innotech, San Leandro, CA) was used to explore variation in spot (clone hybridization) intensity and estimate copy number as described previously [20]. Positive $C$-mos clones were confirmed by PCR using the CMF1/ CMR1 primer pair (Table 1). PCR was performed using the following thermocycler series: $95^{\circ} \mathrm{C}$ denaturation for $5 \mathrm{~min}, 34$ full PCR cycles $\left(94^{\circ} \mathrm{C}\right.$ for $1 \mathrm{~min}, 50^{\circ} \mathrm{C}$ for 1 $\min$, and $72^{\circ} \mathrm{C}$ for $1.5 \mathrm{~min}$ ), and a final $72^{\circ} \mathrm{C} 10 \mathrm{~min}$ extension step. 
Table I: Overgo and primer sequences

\begin{tabular}{lll}
\hline Name & Description & Sequence \\
\hline CMOF & C-mos overgo, forward & TGGAGGATGGCTTATCTCTGAG \\
CMOR & C-mos overgo, reverse & GGCAAATATTGGGCTCAGAGA \\
CR1aOF & CR1a overgo, forward & AGCGGAGGTGGTCAAGCACCT \\
CR1aOR & CR1a overgo, reverse & AAGGTGTTCAATGTAGGTGCTT \\
CR1bOF & CR1b overgo, forward & AATAGGTCCAAGGAGGTATAC \\
CR1bOR & CR1b overgo, reverse & CCGATAGAGGGAAGTATCACC \\
CMF1 & C-mos forward primer1 & ATCACGGCAGAGCTTCTGGG \\
CMR1 & C-mos reverse primer1 & TGGCAAATATTGGGCTCAG \\
CMF2 & C-mos forward primer 2 & GTTGTGCAAGATCGAGACT \\
CMR2 & C-mos reverse primer 2 & GACGTAACTGGGCTACATTC \\
\hline
\end{tabular}

Subcloning and sequencing of the $\mathbf{C}$. porosus $\mathbf{C}$-mos gene A BAC clone containing the $C$. porosus $C$-mos gene was digested with BamHI and HindIII at $37^{\circ} \mathrm{C}$ for $1 \mathrm{hr}$ followed by heating to $65^{\circ} \mathrm{C}$ for $10 \mathrm{~min}$. The cloning vector pCRII-TOPO (Invitrogen, Carlsbad, CA) was likewise double-digested, purified by electrophoresis on a $1 \% \mathrm{w} / \mathrm{v}$ agarose gel, and isolated from agarose using a Qiagen (Valencia, CA) QiaQuick Gel Extraction kit. Ligation was performed at $16^{\circ} \mathrm{C}$ for $16 \mathrm{hrs}$. The ligation mixture was used to transform chemically competent Invitrogen (Carlsbad, CA) One Shot TOP10 cells according to the manufacturer's instructions. Subclones were plated and 40 were screened by PCR using the C-mos primers CMF1 and CMR1 (Table 1). One positive subclone, which was shown by gel electrophoresis to contain a $3.7 \mathrm{~kb}$ insert, was sent to SeqWright (Houston, TX) for cycle sequencing using the CMF1 and CMR1 primers and two additional primers (CMF2 and CMR2 - Table 1). Use of a combination of primers was intended to extend the target area so that it would encompass the entire $C$-mos coding sequence and several hundred bases 5 ' and 3 ' of the coding region. Base-calling and assembly of sequence reads were performed using Phred and Phrap, respectively [21-23]. Trimming of the assembled C-mos sequence was conducted using Cross_Match [23]. The 3576 bp product was submitted to GenBank and assigned the accession FJ011695.

\section{Results and discussion BAC library coverage}

The C. porosus BAC library consists of 101,760 individual clones stored in 265 bar-coded 384-well microtiter plates. Not I digestion and PFGE of 768 BAC clones indicates an average clone insert size of $102 \mathrm{~kb}$ (Figure 2) with $70.5 \%$ of clones possessing inserts $>100 \mathrm{~kb}, 24.2 \%$ with inserts between 50 and $100 \mathrm{~kb}$, and 5.3\% with inserts smaller than $50 \mathrm{~kb}$. Internal NotI sites are present in $41.6 \%$ of PFGE-examined BAC clones (Figure 2), and 1.3\% of clones are probable false positives, i.e., they possess a vector band but no insert band(s). Collectively, the entire
BAC library represents $10.2 \mathrm{~Gb}$ of crocodile genomic DNA [i.e., 101,760 clones $\bullet 102 \mathrm{~kb} /$ clone $\bullet(1-0.013)=10.2 \mathrm{~Gb}$ ].

The exact genome size of C. porosus is unknown. However, measurements made for two other Crocodylus species ( $C$. siamensis and C. niloticus) [24] are both $2778 \mathrm{Mb}$. Assuming the $C$. porosus genome size is similar to those of these closely allied taxa, we estimate that the library affords $3.7 \times$ coverage (i.e., $10.2 \mathrm{~Gb} \div 2778 \mathrm{Mb}=3.7$ ) of the $C$. porosus genome. Theoretically, this level of coverage affords $98 \%$ probability of finding any given genomic sequence at least once in the library [25].

\section{Survey of CRI elements in crocodile genome}

CR1 elements are non-LTR retrotransposons existing in high copy numbers in bird and reptile genomes [26-28]; there are about 100,000 CR1 elements in the chicken genome [26]. CR1 retrotransposons are considered excellent markers for molecular phylogenetic and population genetic studies [29,30]. Initial studies on the sequences from the 21 BAC clones of Alligator mississippiensis availa-

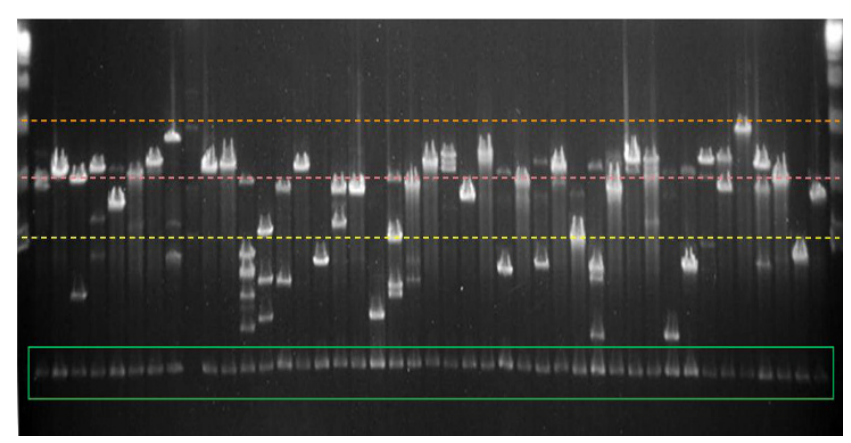

Figure 2

Notl digest of random $C$. porosus BAC clones. The first and last lanes contain a DNA ladder. Molecular weights of 50,100 , and $150 \mathrm{~kb}$ are indicated by yellow, pink, and orange dotted lines, respectively. The $7.4 \mathrm{~kb}$ vector band is visible at the bottom of most lanes (green rectangle). The average insert size is $102 \mathrm{~kb}$. 
ble in GenBank [ $\underline{\mathrm{AC} 164519.3}, \underline{\mathrm{AC} 154087.3}, \underline{\mathrm{AC} 161341.3}$, AC165215.2, AC162159.2, AC155801.3, AC155802.2, AC154170.2, AC155800.2, $\mathrm{AC155799.2}, \mathrm{AC154169.2}$ AC154945.2, AC154088.2, AC149028.2, AC148923.3, AC149025.3，AC148578.2， AC149029.2，AC149026.2， AC148964.2, and AC149027.1] revealed that at least two CR1 subfamilies, referred to here as CR1a and CR1b, have recently been active in crocodilian genomes. This observation is consistent with Shedlock et al. (2007) in which the authors suggested that multiple CR1 lineages may have been active in alligators. In addition to A. mississippiensis, CR1a and CR1b have been identified in Crocodylus moreletii, and Osteolaemus tetraspis (D. Ray, unpublished) and consensus sequences for conserved regions of these elements have been generated (see Additional File 1, Table S1).

To explore CR1 distribution in C. porosus, macroarrays were screened with CR1b-derived overgos or a combination of CR1a and CR1b overgos. Comparison of the CR1b- and CR1a/b-probed macroarrays revealed that the CR1a and CR1b subfamilies are not distinguishable in our assay, i.e., virtually no differences in hybridization pattern and intensity were observed when comparing the CR1b and CR1a/CR1b filters (data not shown). It was clear, however, that elements similar to CR1a and b are fairly abundant in C. porosus. Examination of one-quarter of the CR1a/b-probed macroarray (Figure 3A) indicates that $8.9 \%$ of clones show hybridization to the CR1a/b overgos while CR1b overgo hybridization to a filter stamped with the contents of a single 384-well plate from the BAC library suggests that $12.8 \%$ of clones ( 49 of 384 ) are positive for the CR1b overgo (Figure 4). Densitometric analysis of the macroarray reveals that there is a six-fold variation in positive clone hybridization intensity. If the lightest, but clearly positive hybridization signals represent clones containing one copy of a CR1a/b element and if the darkest clones contain six elements, there would be approximately 19,754 copies of CR1a/b in the C. porosus genome [see [20] for calculation method]. However, there is the possibility that macroarray exposure conditions were such that only clones with multiple copies of CR1a/ b elements appear positive; inclusion of a single-copy sequence control on the macroarray could be used to test this possibility. Moreover, the use of overgos (each pair representing only $36 \mathrm{bp}$ ) rather than whole CR1 sequences clearly limits hybridization to those elements where the regions corresponding to the overgos have been conserved. Based on analysis of $2.5 \mathrm{Mb}$ of BAC end sequence, Shedlock [9] estimated the number of CR1 elements in Alligator mississippiensis at 408,000 copies. While A. mississippiensis and C. porosus are separated by 100 million years of evolution [31], it seems reasonable that they might have similar total numbers of CR1 elements. Consequently, the C. porosus copy number estimate of 19,754

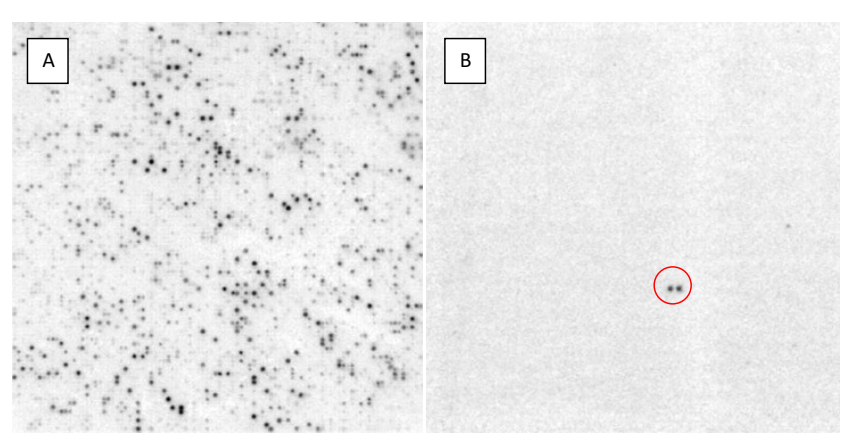

Figure 3

Exploring the $C$. porosus genome using macroarray analysis. (A) One-quarter of a C. porosus macroarray hybridized with the overgo probes CRIa and CRIb. (B) One-quarter of a macroarray showing a BAC (double-spot, red circle) recognized by our $C$-mos overgo. This BAC was isolated and used to sequence the complete $C$-mos gene.

should be viewed as a minimum number of CR1a/b elements, not total CR1 elements, in the C. porosus genome.

Statistical analysis of the macroarray data indicates that CR1a/b elements are not randomly distributed throughout the C. porosus genome. The macroarray contains 18,432 individual clones with an average insert size of $102 \mathrm{~kb}$. Consequently, a single macroarray represents roughly 0.68 genome equivalents, i.e., $(18,432 \bullet 102 \mathrm{~kb}) \div$ $2778 \mathrm{Mb}$. If the crocodile genome contains 19,754 copies of CR1a/b, then we would expect approximately 13,369 copies of CR1a/b per macroarray, and if these were dis-

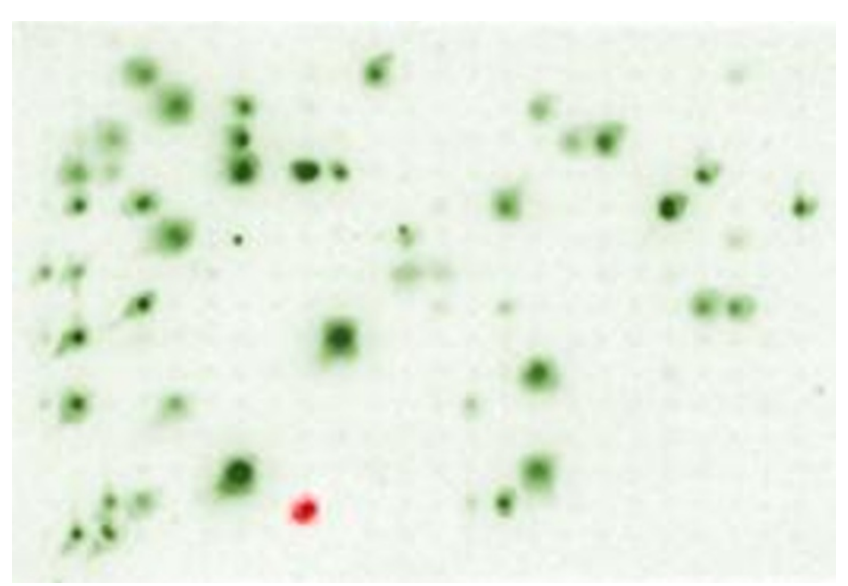

Figure 4

Hybridization of CRI and C-mos overgos to arrays of one 384-well microtiter plate. Images were colorized and digitally merged using Adobe Photoshop. The BAC positive for $C$-mos is indicated in red while clones showing hybridization to CRIb are green. The C-mos clone exhibits no visible co-hybridization with $C R I b$. 
tributed randomly we would expect, on average, 0.73 copies of CR1a/b per clone. However, only $8.9 \%$ of clones on the macroarray show hybridization to the CR1a/b probes. To test whether such a distribution is likely by chance, we can formulate the problem as a statistical "urn model." Suppose we have 18,432 urns, and we drop 13,369 balls into them at random. In such a case, classical statistical asymptotic theory [32] describes the distribution of the number of occupied (or empty) urns. In this experiment we found 1,203 occupied and 17,229 empty urns. The null and alternative hypotheses are as follows:

$H_{0}$ : The allocation is completely random;

$$
H_{\mathrm{A}}: \operatorname{Not} \mathrm{H}_{0} \text {. }
$$

Under $H_{0}$, the number of empty urns is (approximately) normally distributed with mean 8,924 and standard deviation $\approx 40$ [33] (verified both theoretically and by simulation), so the observed number of empty urns (i.e., 17,229) is more than 200 standard deviations above the mean, and hence is almost impossible under $H_{0}$ (the formal $p$ value is zero to 32 decimal places). We therefore conclude that the distribution of CR1a/b is non-random.

A project is underway that will involve sequencing some CR1 positive BAC clones from C.porosus so that we may (among other things) compare the structure and distribution of CR1 elements in the Alligator and Crocodylus genomes. The sequence data can then be used for evolutionary analyses among crocodilians, birds, and nonarchosaur reptiles.

\section{Identification of a crocodile C-mos gene containing BAC clone}

A randomly selected macroarray was hybridized with the C-mos overgos (Table 1), and fortuitously one of the 18,432 double-spotted clones on the array exhibited a positive signal (Figure 3 ). The plate and well address of the clone was determined based upon the macroarray number, the location of the positive signal on the macroarray, and the spatial relationship between the two spots [see [34]]. To make sure that the correct clone was identified, a hand-held plate gridding/replicating device was used to stamp two nylon filters with the clones in the 384-well plate believed to contain the clone of interest. Blot hybridization using the $C$-mos overgo probes verified that the plate and well address obtained from the filter were correct (Figure 4). The duplicate filter was probed with the CR1b overgos. Of note, the C-mos positive clone shows no visible hybridization with the CR1b sequence (Figure 4). PCR with the CMF1 and CMR1 primers was used to independently verify the presence of the C-mos locus in the positive BAC clone.

\section{The C. porosus $\mathbf{C}$-mos gene}

Subcloning was used to isolate a $3.7 \mathrm{~kb}$ region containing the $C$-mos locus. Cycle sequencing using the CMF1, CMF2, CMR1, and CMR2 primers (Table 1) and assembly of the reads resulted in production of a continuous $3,576 \mathrm{bp}$ sequence [GenBank:FJ011695]. This sequence contains the entire coding sequence (CDS) for C-mos as well as > $1000 \mathrm{bp}$ upstream and downstream of the CDS. Like most characterized C-mos sequences [35], C. porosus C-mos possesses a single ORF. The ORF, which starts at base 1313 and ends with the stop codon TGA (bases 2366-2368), codes for a 351 amino acid protein. Alignment of the $C$. porosus C-mos CDS with those of chicken, zebra finch, and green anole orthologs (see Additional File 1, Figures S1 and S2 for alignments) reveals considerable nucleotide and amino acid conservation (Table 2). Interestingly, the C. porosus CDS is six nucleotides ( 2 amino acids) longer than the chicken, zebra finch, and green anole C-mos genes. These two additional amino acids are adjacent to each other and are located at the C-terminal end of the $C$. porosus C-mos protein (see Additional File 1, Figures S1 and S2).

\section{Crocodilian sequence and comparative genomics}

Comparative genomics research is a burgeoning field with high potential to increase our understanding of the structure, function, and evolution behind the diversity of life. However, the primary focus of most efforts over the past several years has been on comparisons among mammals. For example, Miller et al. recently created a 28-way alignment of available vertebrate genomes in which only eight taxa, Gallus, Anolis, Xenopus and five fish represent the entirety of non-mammalian vertebrates. Understanding the evolution and interrelationships among all amnotes will be severely hindered by this lack of diversity. Ongoing

Table 2: Similarity of complete coding sequences of four C-mos genes

\begin{tabular}{|c|c|c|c|}
\hline Organism & $\begin{array}{l}\text { GenBank accession or } \\
\text { reference to database from } \\
\text { which sequence was mined }\end{array}$ & $\begin{array}{l}\text { Nucleotide identities } \\
(\%) \text { with respect to } C . \\
\text { porosus }\end{array}$ & $\begin{array}{l}\text { Amino acid identities } \\
(\%) \text { with respect to } C . \\
\text { porosus }\end{array}$ \\
\hline Crocodylus porosus & F]011695 & 100.0 & 100.0 \\
\hline Gallus gallus & M194I2.I & 77.9 & 76.5 \\
\hline Taeniopygia guttata & [37] & 76.8 & 75.6 \\
\hline Anolis carolinensis & [37] & 69.6 & 71.6 \\
\hline
\end{tabular}


projects to sequence the green anole (Sqamata) and the painted turtle (Chelonia) will help correct the disparity but one significant lineage of the amniote tree remains to be addressed - Crocodylia. It is our hope that the generation of this library will facilitate genomics research in this critical lineage.

\section{Conclusion}

We have constructed a high quality 3.7× BAC library for Crocodylus porosus and demonstrated the library's utility as a genomics tool. We are currently screening the library with other genes and repeat sequences as a means of investigating the structure of the Australian saltwater crocodile genome and facilitating comparative genomics research among archosaurs. Copies of the BAC library, individual clones, and macroarrays can be obtained from the Mississippi Genome Exploration Laboratory [14].

\section{Competing interests}

The authors declare that they have no competing interests.

\section{Authors' contributions}

The project was conceived through discussions between DGP and DAR. XS constructed the BAC library and performed all bench research in the lab of DGP. Experiments were designed by XS with the input of DGP and DAR. DAR provided sequence data for CR1 analyses of the library and made arrangements associated with acquisition of crocodile blood. JAB performed the statistical analysis associated with CR1 distribution. All authors were involved in manuscript writing and editing. The final version of the manuscript was read and approved by all authors.

\section{Additional material}

\section{Additional file 1}

Table S1. Consensus sequences of highly conserved portions of crocodilian CR1 $a$ and CR1b subfamily elements. Table S2. Putative C-mos CDS for platypus mined from the current genome assembly amended so that the two overlapping but out of frame ORFs are combined into a single presumed C-mos CDS. Figure S1. MUSCLE-based nucleotide alignment of the complete coding sequences of A. carolinensis, C. porosus, G. gallus, and $\mathrm{T}$. guttata C-mos genes. Figure S2. MUSCLE-based amino acid alignment of the complete coding sequences of A. carolinensis, C. porosus, G. gallus, and T. guttata C-mos genes.

Click here for file

[http://www.biomedcentral.com/content/supplementary/14712164-10-S2-S9-S1.pdf]

\section{Acknowledgements}

We thank Sally Isberg, Lee Miles, and Travis Glenn for helping us obtain the crocodile blood and Lauren Dembeck for conducting the initial CRI analyses of $A$. mississippiensis, $O$. tetraspis, and $C$. moreletii. This research was supported, in part, by USDA award ARS-58-6402-7-24I (DGP) and National
Science Foundation award DBI-042 I7I7 (DGP). DAR was supported by the Eberly College of Arts and Sciences at WVU.

This article has been published as part of BMC Genomics Volume 10 Supplement 2, 2009: Proceedings of the Avian Genomics Conference and Gene Ontology Annotation Workshop. The full contents of the supplement are available online at http://www.biomedcentral.com/ $147 \mid-2164 / 10$ ? issue $=\$ 2$

\section{References}

I. Janke A, Arnason U: The complete mitochondrial genome of Alligator mississippiensis and the separation between recent archosauria (birds and crocodiles). Mol Biol Evol 1997, I4: I266-I 272.

2. Kumar S, Hedges SB: A molecular timescale for vertebrate evolution. Nature 1998, 392:917-920.

3. Dessauer HC, Glenn TC, Densmore LD: Studies on the molecular evolution of the Crocodylia: footprints in the sands of time. J Exp Zool 2002, 294:302-3II.

4. Willis RE, McAliley LR, Neeley ED, Densmore LD III: Evidence for placing the false gharial (Tomistoma schlegelii) into the family Gavialidae: inferences from nuclear gene sequences. Mol Phylogenet Evol 2007, 43:787-794.

5. Benton MJ, Donoghue PC: Paleontological evidence to date the tree of life. Mol Biol Evol 2007, 24:26-53.

6. Iwabe N, Hara Y, Kumazawa Y, Shibamoto K, Saito Y, Miyata T, Katoh K: Sister group relationship of turtles to the bird-crocodilian clade revealed by nuclear DNA-coded proteins. Mol Biol Evol 2005, 22:810-8I3.

7. International Chicken Genome Sequencing Consortium: Sequence and comparative analysis of the chicken genome provide unique perspectives on vertebrate evolution. Nature 2004, 432:695-716.

8. Slate J, Hale MC, Birkhead TR: Simple sequence repeats in zebra finch (Taeniopygia guttata) expressed sequence tags: a new resource for evolutionary genetic studies of passerines. $B M C$ Genomics 2007, 8:52.

9. Shedlock AM, Botka CW, Zhao S, Shetty J, Zhang T, Liu JS, Deschavanne PJ, Edwards SV: Phylogenomics of nonavian reptiles and the structure of the ancestral amniote genome. Proc Natl Acad Sci USA 2007, 104:2767-2772.

10. Zhang $\mathrm{H}-\mathrm{B}, \mathrm{Wu} \mathrm{C}$ : BACs as tools for genome sequencing. Plant Physiol Biochem 2001, 39:1 195-209.

II. Sundquist A, Ronaghi M, Tang H, Pevzner P, Batzoglou S: Wholegenome sequencing and assembly with high-throughput, short-read technologies. PLOS ONE 2007, 2:e484.

12. Miyake T, Amemiya CT: BAC libraries and comparative genomics of aquatic chordate species. Comp Biochem Physiol C Toxicol Pharmacol 2004, 138:233-244.

13. Darwin Crocodile Farm [http://www.crocfarm.com.au]

14. Mississippi Genome Exploration Laboratory (MGEL) [http:/ /www.mgel.msstate.edu]

15. Peterson DG, Tomkins JP, Frisch DA, Wing RA, Paterson AH: Construction of plant bacterial artificial chromosome (BAC) libraries: An illustrated Guide. J Agric Genomics 2000, 5: [http:// wheat.pw.usda.gov/jag/].

16. Chalhoub B, Belcram $\mathrm{H}$, Caboche M: Efficient cloning of plant genomes into bacterial artificial chromosome (BAC) libraries with larger and more uniform insert size. Plant Biotechnol J 2004, 2: 181-188.

17. NCBI Probe Database [http://www.ncbi.nlm.nih.gov/projects/ genome/probe/doc/TechOvergo.shtml]

18. McPherson JD, Marra M, Hillier L, et al.: A physical map of the human genome. Nature 200I, 409:934-94I.

19. CHORI BACPAC Resources Center [http://bacpac.chori.org/ overgohyb.htm]

20. Peterson DG, Schulze SR, Sciara EB, et al.: Integration of Cot analysis, DNA cloning, and high-throughput sequencing facilitates genome characterization and gene discovery. Genome Res 2002, I 2:795-807.

21. Ewing B, Hillier L, Wendl MC, Green P: Base-calling of automated sequencer traces using Phred. I. Accuracy assessment. Genome Res 1998, 8: 175-185.

22. Dresser ME, Ewing DJ, Conrad MN, Dominguez AM, Barstead R, Jiang $\mathrm{H}$, Kodadek T: DMCI functions in a Saccharomyces cerevisiae 
meiotic pathway that is largely independent of the RAD5 I pathway. Genetics 1997, 147:533-544.

23. Phred, Phrap, Consed [http://www.phrap.org]

24. Capriglione $T$, Olmo E, Odierna G, Improta B, Morescalchi A: Cytofluorometric DNA base determination in vertebrate species with different genome sizes. Basic Appl Histochem 1987, 31:119-126.

25. Plomion C, Chagné D, Pot D, et al:: The Pines. In Genome Mapping and Molecular Breeding in Plants, Forest Trees Volume 7. Edited by: Kole CR. Heidelberg, Berlin, New York, Tokyo: Springer; 2007:29-78.

26. Chen ZQ, Ritzel RG, Lin CC, Hodgetts RB: Sequence conservation in avian CRI: an interspersed repetitive DNA family evolving under functional constraints. Proc Natl Acad Sci USA |99|, 88:58|4-58|8.

27. Vandergon TL, Reitman M: Evolution of chicken repeat I (CRI) elements: evidence for ancient subfamilies and multiple progenitors. Mol Biol Evol 1994, I I:886-898.

28. Shedlock AM: Phylogenomic investigation of CRI LINE diversity in reptiles. Syst Biol 2006, 55:902-91I.

29. Ray DA, Xing J, Salem AH, Batzer MA: SINEs of a nearly perfect character. Syst Biol 2006, 55:928-935.

30. Ray DA, Walker JA, Batzer MA: Mobile element-based forensic genomics. Mutat Res 2007, 61 6:24-33.

31. Roos J, Aggarwal RK, Janke A: Extended mitogenomic phylogenetic analyses yield new insight into crocodylian evolution and their survival of the Cretaceous-Tertiary boundary. Mol Phylogenet Evol 2007, 45:663-673.

32. Kolchin VF, Sevastianov BA, Chistyakov VP, Balakrishnan AV: Random Allocations New York: Halsted Press; 1978.

33. Holst L: Limit Theorems for Some Occupancy and Sequential Occupancy Problems. Annals Mathemat Stat 197I, 42:167I-I680.

34. Clemson University Genomics Institute (CUGI) - Filter Illustration [http://www.genome.clemson.edu/protocols.shtml]

35. Saint KM, Austin CC, Donnellan SC, Hutchinson MN: C-mos, a nuclear marker useful for squamate phylogenetic analysis. Mol Phylogenet Evol 1998, 10:259-263.

36. Brochu CA: Progress and future directions in archosaur phylogenetics. J Paleontology 200I, 75: I I85-I20I.

37. Washington University Genome Sequencing Center [http:// genome.wustl.edu]

Publish with Bio Med Central and every scientist can read your work free of charge

"BioMed Central will be the most significant development for disseminating the results of biomedical research in our lifetime. "

Sir Paul Nurse, Cancer Research UK

Your research papers will be:

- available free of charge to the entire biomedical community

- peer reviewed and published immediately upon acceptance

- cited in PubMed and archived on PubMed Central

- yours - you keep the copyright

Submit your manuscript here:

http://www.biomedcentral.com/info/publishing_adv.asp
BioMedcentral 